\title{
Tratamiento del aborto séptico y la amnionitis con sulbactam/ampicilina
}

\author{
EXPERIENCIA EN EL INSTITUTO MATERNO INFANTIL DE BOGOTA
}

\author{
Dres. Consuelo Arteaga Diaz*, Armando Lozano Carrillo**
}

\begin{abstract}
RESUMEN. Para confirmar la eficacia y seguridad de sulbactam/ampicilina, se lleva a cabo una evaluación abierta, no comparativa, en 26 pacientes que acudieron al servicio de Sépticas del I.M.I. por aborto séptico o amnionitis. Se administró el tratamiento antibiótico inicialmente por vía parenteral, generalmente intravenosa, continuándose por vía oral. Las dosis utilizadas variaron, dependiendo de la severidad y la duración de la infección, administrándose un promedio de 6 gramos diarios en los primeros dos días, dosis que se redujo por el resto del tratamiento. Los resultados clínicos fueron excelentes en el $85 \%$ (22 pacientes). Una sola paciente tuvo un efecto secundario leve. Se concluye que sulbactam/ampicilina es una excelente alternativa en el manejo de las infeciones de origen obstétrico.
\end{abstract}

PALABRAS CLAVES: Aborto séptico, amnionitis, sulbactam/ampicilina, eficacia, seguridad.

SUMMARY. To confirm the efficacy and safety of sulbactam/ampicillin, we undertook an open, non comparative evaluation in 26 patients admitted to the Septic Ward of the Instituto Materno Infantil of Bogotá because of septic abortion or amnionitis. The antibiotic was initially administered by the IV route which was then switched to the oral. The employed dosage varied according to the severity and duration of infection, with a mean of 6 grams for the first two days, with progressive decreases for the rest of the treatment. Clinical results were considered excellent in $85 \%$ ( 22 patients). Only one patient had a mild side effect. Based on these results, we conclude that sulbactam/ampicillin is an excellent alternative in the management of obstetric borne infections.

KEY WORDS: Septic abortion, amnionitis, sulbactam/ampicillin, efficacy, safety.

\section{Introducción}

Dentro de los procesos infecciosos observados en todas las especialidades médicas, el aborto séptico y la amnionitis figuran entre los más temidos debido a la elevada morbi-mortalidad que generan cuando su diagnóstico y tratamiento no se realizan oportunamente. Esto se debe a que la etiología de las infecciones del tracto genital femenino es, por lo general, polimicrobiana y frecuentemente con presencia de anaerobios; por el contrario, en medicina interna $(1,2) \mathrm{su}$ naturaleza es básicamente monobacteriana, aeróbica. Además, en ginecobstetricia, el problema creciente de la resistencia bacteriana, incrementado notablemente en los últimos años $(3,4)$ requiere terapias agresivas que cubran la mayoría, si no la totalidad, de los patógenos involucrados $(1,5)$.

La penicilina y sus derivados, entre ellos la ampicilina, cumplen todavía un papel muy importante en el armamentario terapéutico de nuestra especialidad, debido especialmente a su seguridad, que les permite ser empleadas durante la gestación. El mayor inconveniente ha sido su progresiva

\footnotetext{
* Gineco-Obstetra de Planta, I.M.I.

** Profesor Asociado. Jefe Unidad de Sépticas. Depto. de Obstetricia y Ginecología. Universidad Nacional. Instituto Materno Infantil, Bogotá.
}

pérdida de espectro, debido a la creciente aparición de bacterias productoras de betalactamasas, las cuales, aún sin ser las causantes de la infección, conducen a la pérdida de eficacia de los antibióticos betalactámicos (4).

Los inhibidores suicidas de las betalactamasas, asociados a los antibióticos betalactámicos, permiten recobrar e inclusive ampliar, el espectro original del agente anti-infeccioso. Esto es lo que sucede con la asociación sulbactam, y la ampicilina, que se comporta como una cefalosporina de segunda generación. Tiene esta asociación la ventaja adicional de ser monoterapia, lo cual facilita el manejo de la paciente, reduciendo los costos y los riesgos de la polifarmacia antibacteriana tradicional en ginecobstetricia $(1,6,7)$.

Basados en este razonamiento se decidió evaluar la eficacia y seguridad de esta nueva combinación antibiótica en un grupo de pacientes ginecobstétricas severamente infectadas, siguiendo el protocolo aprobado por el Comité de Investigaciones del Instituto Materno Infantil.

\section{Material y métodos}

El grupo estudiado quedó constituido por pacientes hospitalizadas en el servicio de Sépticas del Instituto Materno Infantil de Bogotá, que ingresaron con diagnóstico de infec- 
ción de origen obstétrico (aborto) o como complicación infecciosa posterior a un parto, bien por vía vaginal o por cesárea.

Para ingresar al estudio la paciente debía estar hospitalizada, ser mayor de 15 años, y tener diagnóstico de aborto séptico o amnionitis. Cuando estaba recibiendo otros antimicrobianos sin éxito, éstos debían suspenderse antes de iniciar sulbactam/ampicilina. Todas las pacientes dieron su aceptación escrita de inclusión.

No se admitieron pacientes con infección terminal o con enfermedades (cáncer, inmunodepresión, etc.) que no permitieran una adecuada valoración de eficacia. Igualmente, aquellas con infecciones concomitantes (tuberculosis), o historia de alergia a las penicilinas, y sulbactam. Tampoco se permitió el ingreso de pacientes tratadas durante el último mes con otro medicamento en investigación, o que presentaran disfunción hepática o biliar severas, o pretendieran donar sangre durante el estudio. El uso concomitante de otros antimicrobianos no estaba permitido.

Antes de iniciar tratamiento se practicaban los exámenes de laboratorio y microbiología y, sin esperar sus resultados, se empezaba la terapia por vía intravenosa, la cual, de acuerdo con la evaluación de la paciente, se podía cambiar a la vía intramuscular o a la oral.

La evaluación previa, así como los controles diarios durante el tiempo de hospitalización, incluían los signos y síntomas de infección, y el estado general de la paciente. Durante el tratamiento también se investigaba la presencia de efectos secundarios. Al finalizar, se realizaban nuevamente todos los exámenes clínicos y paraclínicos para comparar las modificaciones logradas con la terapia.

Los criterios para valorar la eficacia clínica fueron los siguientes: Excelente: desaparición de todos los signos/síntomas relacionados con el estado agudo y retorno de la temperatura a lo normal; Buena: recuperación satisfactoria, o desaparición parcial de los signos/síntomas del estado agudo de la enfermedad; Mala: no hubo mejoría significativa de los signos y síntomas basales.

Para evaluar la seguridad y tolerancia a la droga se tuvieron en cuenta los siguientes parámetros: Excelente: sin efectos secundarios; Buena: efectos secundarios leves y/o tolerables, que no requirieron tratamiento sintomático; Regular: presencia de efectos secundarios que requirieron la administración de tratamiento sintomático; Mala: efectos secundarios severos, que requirieron la administración de tratamiento sintomático y la suspensión del medicamento en estudio.

Durante los primeros días la administración de sulbactam/ ampicilina fue intravenosa, a razón de 1.5 a 3 gramos cada 6 a 8 horas, dependiendo de la severidad de la infección. De acuerdo con la evolución, se podían modificar tanto la dosis como la vía de administración del antibiótico, pudiendo escogerse la intramuscular, a razón de $1.5 \mathrm{~g}$ cada 12 horas, o la oral, utilizando para tal efecto la sultamicilina en tabletas, 0.750 a 1.5 gramos diarios repartidos en dos tomas.

\section{Resultados}

DEMOGRAFIA. Se incluyeron 26 pacientes cuya edad promedio fue de 24 años con una desviación estándar de
6.03. Las edades mínimas y máximas fueron 17 y 42 años respectivamente (Tabla 1).

DIAGNOSTICO - DURACION. Diecinueve pacientes (73\%) presentaban amnionitis, 13 postcesárea y 6 postparto vaginal; las restantes acudieron por aborto séptico ( 7 pacientes $-27 \%$ ).

La duración de la infección antes de acudir al hospital varió entre 1 y 2 días en el $54 \%$ ( 14 pacientes), 3 a 5 días en el 27\% (7 pacientes) y más de 5 días en el $19 \%$ (5 pacientes). El promedio fue de 4 días con una desviación estándar de 4.03.

EXAMENES DE LABORATORIO. Antes del tratamiento, el cuadro hemático con V.S.G. resultó francamente anormal en la totalidad de los casos; sin embargo al término del mismo hubo cambios notorios, tal como se puede apreciar en la Tabla 2. El perfil bioquímico, así como los exámenes de orina, no mostraron desviación de los valores normales antes ni después de la terapia.

Aunque se tomaron algunos cultivos pre-tratamiento, esto no pudo realizarse en todos los casos, debido al tipo de patología infecciosa de cada uno. Por esta razón, no pudo hacerse una correlación clínico-bacteriológica.

ADMINISTRACION DE SULBACTAM/AMPICILINA Y DURACION DEL TRATAMIENTO. La totalidad de las pacientes recibieron en los dos primeros días una dosis total de 6 gramos diarios por vía intravenosa, divididos en 1.5 gramos cada seis horas; 8 de las pacientes continuaron su tratamiento por vía oral con las tabletas de sultamicilina, a dosis que variaron entre $375 \mathrm{mg}$ y $1.5 \mathrm{~g}$ dos veces al día. El resto de las pacientes continuó con tratamiento parenteral por vía intravenosa o intramuscular, ajustando las dosis de acuerdo con la evolución de cada caso.

La duración media del tratamiento fue de 8 días (D.E. $3.61)$. El $57.7 \%$ de las pacientes (15) recibieron tratamiento durante 6 a 7 días.

\begin{tabular}{ccc|}
\multicolumn{1}{c}{ Tabla 1 } \\
\multicolumn{1}{c}{ EDAD } \\
\hline EDAD(años) & No. CASOS & PORCENTAJE \\
\hline$<=20$ & 8 & 30.77 \\
$21-30$ & 15 & 57.69 \\
$>30$ & 3 & 11.54 \\
\hline
\end{tabular}

Tabla 2

CUADRO HEMATICO

\begin{tabular}{|cccccc|}
\hline & INICIAL & D.E. & FINAL & D.E. & VALOR p \\
\hline Hemoglobina & 10.7 & 2.0 & 12.0 & 1.7 & 0.025 \\
Hematocrito & 32.0 & 6.3 & 36.0 & 5.2 & 0.025 \\
V.S.G. & 43.0 & 21.0 & 40.0 & 18 & N.S. \\
Leucocitos & 11872 & 2596 & 8294 & 1755 & 0.0000001 \\
Neutrofilos & 80.0 & 8.7 & 65.0 & 10.2 & 0.0001 \\
Linfocitos & 18.0 & 8.0 & 32.0 & 9.6 & 0.0001 \\
\hline
\end{tabular}

Tabla 3

EFICACIA Y SEGURIDAD

\begin{tabular}{|crrrrr|}
\hline CRITERIO & \multicolumn{2}{c}{ EFICACIA } & \multicolumn{2}{c|}{ SEGURIDAD } \\
& Número & Porcentaje & Número & Porcentaje \\
\hline Excelente & 22 & 84.62 & 25 & 96.15 \\
Buena & 1 & 3.85 & 1 & 3.85 \\
Mala & 3 & 11.53 & - & - \\
\hline
\end{tabular}


EFICACIA. En la Tabla 3 se pueden observar estos resultados, destacándose el elevado número de casos excelentes (22). Entre resultados excelentes y buenos se logra un $88.5 \%$, lo cual confirma los hallazgos de diversos investigadores en otras partes del mundo $(6,7,8)$.

SEGURIDAD. La seguridad se valoró como Excelente en 25 casos $(96.15 \%)$ y como Buena, un caso $(3.85 \%)$. Este último corresponde a un rash leve que desapareció sin necesidad de interrumpir el tratamiento.

\section{Discusión y conclusiones}

Con el presente estudio comprobamos los excelentes efectos terapéuticos de la asociación sulbactam/ampicilina en el manejo de las infecciones ginecobstétricas más comunes: el aborto séptico y la amnionitis.

La observación sobre la resistencia bacteriana a los antibióticos se hizo muy rápidamente después de la introducción de la terapia antibiótica en los años 40 y tiene creciente importancia hoy $(2,3)$; además se ha demostrado que el principal mecanismo para la resistencia bacteriana a los antibióticos betalactámicos es la presencia de betalactamasas (4).

La infección ginecobstétrica es de naturaleza polimicrobiana de tipo aerobio y anaerobio e involucra muchos organismos productores de betalactamasas $(1,2,4,5)$.

El desarrollo de nuevos antibióticos contra anaerobios y productores de betalactamasas es de gran importancia en ginecobstetricia dada la alta morbi-mortalidad que estas bacterias causan en este grupo de pacientes $(1,5)$.

La complicación séptica en obstetricia es particularmente relievante en instituciones como la nuestra, pues constituye no sólo una complicación médica grave, sino que además tiene profundas implicaciones sociales y económicas en el núcleo familiar que involucra a la paciente y a su hijo.

El poder contar con una terapia antibiótica eficaz, bien tolerada y activa sobre bacterias anaerobias y aerobias responsables de la sepsis de origen obstétrico como lo es la asociación sulbactam/ampicilina $(6,7,8)$, permite controlar la infección y acortar el tiempo de estancia hospitalaria sin riesgo tóxico para la madre y el niño.

Por los resultados observados en este estudio podemos concluir que la asociación de sulbactam, un inhibidor de las betalactamasas, con un antibiótico betalactámico muy bien tolerado como lo es la ampicilina, es una excelente alternativa en el manejo de las infecciones de origen obstétricas.

\section{Agradecimientos}

A Laboratorios Pfizer que hizo posible la existencia de este trabajo y particularmente al Dr. Daniel Loboguerrero que fue un asesor permanente y una ayuda invaluable en la ejecución del mismo. A la Dra. Catalina Acevedo por la recolección de los datos, Residente III del Depto. de Obstetricia y Ginecología.

\section{BIBLIOGRAFIA}

1. MONIF, G. Ob-Gyn Infectious Diseases, Second Edition, Core Manual, Infectious Disease Inc (Publishers), 1979; 2-22.

2. STYRT, B.; GORBACH, S. Recent developments in the understanding of the pathogenesis and treatment of anaerobic infections (Second of two parts), NEJM, 1989; 321,5: 298-302.

3. MURRAY, B.E. Problems and Mechanisms of Antimicrobial Resistance. En Antibacterial Agents: Pharmacodynamics, Pharmacology, New Agents, Infectious Disease Clinics of North America, 1989; 3 (3): 423-439.

4. STYRT, B.; GORBACH, S. Recent developments in the understanding of the pathogenesis and treatment of anaerobic infections (First of two parts), NEJM, 1989; 321: 240-244.
5. FINEGOLD, S.M. Anaerobic Bacteria. Their role in infection and their management. Postgraduate Medicine, 1987; 81 (8): 141-147.

6. BENSON, J.M.; NAHATA, M.C. Sulbactam/ampicillin, a new betalactamase inhibitor/beta-lactam antibiotic combination. Drug InteIligence and Clinical Pharmacy, 1988; 22: 534-541.

7. CAMPOLI-RICHARDS, D.M.; BRODGEN, R.N. Sulbactam/ampicillin. A review of its antibacterial activity, pharmacokinetic properties and therapeutic use. Drugs, 1989; 33: 577-609.

8. HEMSELL, D.L.; HEARD, Mc.; HEMSELL, P.G.; NOBLES, B.J. Sulbactam/ampicillin versus cefoxitin for Uncomplicated and complicated acute pelvic inflammatory disease. Drugs, 1988; 35 (supp 7). $39-42$. 